\title{
The Role of Knowledge Processes in a Business Ecosystem's Lifecycle
}

Amel Attour 1,*

Email amel.attour@gredeg.cnrs.fr

Pierre Barbaroux 2

Email pierre.barbaroux@defense.gouv.fr

${ }^{1}$ University of Nice-Sophia Antipolis - GREDEG, Nice, France

${ }^{2}$ French Air Force Research Centre - Ecole de l'air, Salon de Provence, France

\section{Abstract}

In this article, we investigate the development of a business ecosystem by focusing on the knowledge processes associated with the various phases of its lifecycle. Specifically, we ask: What knowledge processes are involved in the birth, expansion, leadership, and renewal phases of a business ecosystem, and how are these processes linked together to shape its lifecycle? To address this research question, we build on a case study of a near-field communication (NFC) platform ecosystem, which is considered to be an innovative networkcentric organizational form. The findings reveal three knowledge processes: generation, application, and valorization. Together, these knowledge processes enable the performance of a variety of tasks and activities associated with the distinctive phases of a business ecosystem's lifecycle.

\section{Keywords}

Business ecosystem

Knowledge management

Innovation

Lifecycle

\section{Introduction}

Over the last 30 years, firms' innovation practices have changed radically. 
Advances in information and communication technologies (ICT) and increasing competitive pressures have led firms to decentralize R\&D activities. Modern innovation strategies are now focused on harnessing the potential of a wide range of internal capacities (e.g., R\&D, marketing, production, and intellectual property rights) and a variety of external resources.

Over the last decade a fundamental change has occurred in the way innovation is organized. It tended to be concentrated at or near headquarters but is now much more decentralized within the company. Equally significant, innovation activities that used to be carried out in-house by innovating firms themselves are carried out by independent suppliers of knowledge intensive business services (KIBS) or are transferred to key suppliers (Lema et al. 2015, p. 1377).

Major changes in innovation models stem from increased openness in the work performed by commercial firms' R\&D laboratories, exemplified in particular by integration and collaboration among users and suppliers early in the innovation process (e.g., during the design phase). These open and collaborative approaches to innovation rely on knowledge sharing among public and private stakeholders who interact and develop new ideas by (re)combining tangible and intangible assets (Barbaroux 2014; Clarysse et al. 2014).

Deploying interactive and collaborative organizational forms such as business ecosystems (Moore 1993) entails modifying the knowledge management processes developed by firms during various phases of the innovation process. Entrusting all or part of the development of new knowledge concepts during the ideation stage (or invention phase; Arthur 2007) to a third party (e.g., a research laboratory or supplier) raises additional challenges associated with knowledge codification and transfer (Cepeda and Vera 2007; Teece 2007). For example, the knowledge created, even partly, through external relationships should be combined with a firm's internal knowledge. This, in turn, requires the implementation of integration mechanisms that depend on specific capabilities (such as knowledge absorption capacities; Cohen and Levinthal 1990). In addition, the collaborative conceptualization and conversion of new concepts into operational technologies requires new modes of managing partner interactions based on flexible governance structures, transformational leadership, and a balanced integration of knowledge sharing and knowledge control (Amin and Cohendet 2004). Finally, the adoption of interactive and collaborative innovation models impacts how firms manage ideas and knowledge during the commercialization phase. Firms must find ways to deploy appropriation regimes 
that fit with the characteristics of interactive innovation models in terms of knowledge sharing, protection, and valorization (Teece 2010).

By and large, the trend toward increasing levels of collaboration and interaction has altered the way the invention and commercialization phases are managed by innovating firms. If one assumes that "knowledge and innovation are inseparable" (Fidel et al. 2015, p. 1426), then one should consider that knowledge management is inseparable from a firm's innovation model and strategy. However, despite significant advances in the literatures on innovation management and strategic management, there remains a need to improve our understanding of the specificities of knowledge management processes and practices supporting the different phases of new collaborative and interactive models of innovation, i.e., business ecosystems.

Defined as an inter-organizational arrangements or a space of opportunities (Koenig 2013), business ecosystems mobilized an extensive literature in strategic management. Researches mainly investigated the nature and logics of knowledge management processes and organizational competencies supporting the birth of a business (Loilier and Malherbe 2013; Attour and Della Peruta 2014; Attour and Ayerbe 2015; Attour and Barbaroux 2016). When considering the overall lifecycle, the research question is often focused on the role of the focal firm and on the importance of the governance mechanisms in relation to the processes of knowledge management and value creation (Iskia et al. 2014).

The aim of this paper is to fill this gap by analyzing the knowledge management processes associated with the different phases of a business ecosystem's lifecycle. The research question is the following: which knowledge processes are involved in the birth, expansion, leadership, and renewal phases of a business ecosystem, and how are these processes linked together to shape its lifecycle? To explore this issue, we develop a case study of a specific business ecosystem: a near-field communication (NFC) platform called the Sophia-Zen project.

The rest of the article is organized as follows. We begin by defining the different phases of a business ecosystem's lifecycle and identifying the associated knowledge processes mobilized by the different actors participating in the ecosystem's development. Then, we present the research methodology and describe the research context, as well as data collection and analysis procedures. In the two sections that follow, we present the findings of the case study and discuss major implications related to the role of knowledge processes during various phases of a business ecosystem's lifecycle. In the final section, we describe the limitations of our study and suggest promising avenues for future research. 


\section{Business Ecosystem and Knowledge Management}

A business ecosystem, considered to be an innovative organizational form, has several developmental phases (Moore 1993, 1996): birth, expansion, leadership (maturity), and regeneration (or renewal). In the following sections, we show how these phases fit with the invention and commercialization phases that characterize the innovation process (Schumpeter 1939).

\section{The Lifecycle of a Business Ecosystem as an Innovation Process}

Economists traditionally distinguish two phases of innovation: invention and commercialization (Kline and Rosenberg 1986). Together, these two phases define innovation as a process that links together the "perception of market needs" and the "analytical design being taken through development and production to marketing and distribution" (Palmberg 2006, p. 1254). According to Arthur (2007), the invention phase can itself be decomposed into three stages: (a) ideating a basic principle, (b) conceptualizing how to fulfill a need, and (c) translating the basic principle into operational technology. The starting point of the invention phase is thus the identification of an economic opportunity associated with applying one (or several) basic principle(s) to satisfy a real or potential need (Arthur 2007). Economic opportunity may also derive from the discovery of a physical phenomenon (e.g., a scientific discovery) and its economic potential (Arthur 2007). The conceptualization of a business opportunity entails a search for an appropriate way to satisfy the constraints of its realization. The objective is to design a "route" (Arthur 2007) that connects solutions and constraints to the basic principle(s). According to Arthur (2007), p. 280, "it comes as a moment of connection, always a connection, because it connects a problem with a principle — an effect in use - that can handle it." Finally, the resulting concept must be translated into an operational technology if it is to become an innovation. This last stage of the invention phase consists of translating from "mental concept to physical embodiment... Solutions that were conceptual must be produced in physical form, and sub problems that were partially bypassed must be dealt with directly" (Arthur 2007, p. 281). The translation stage is a period of development during which knowledge is accumulated and technological challenges are progressively addressed to produce a functional technology (Arthur 2007, p. 282).

The second phase of the innovation process involves the commercialization of innovation. Two activities run in parallel. First, an innovation must be adopted and diffused throughout appropriate networks (Aarikka-Stenroos et al. 2014). Thus, distribution channels are selected based on customers' needs, the value chain, and the network of partners implicated in the exploitation of the 
innovation. Second, a firm must define an appropriation regime for the value generated through the commercialization of innovation (Milesi et al. 2013; Sternitzke 2010). A firm must choose a legal framework in order to protect its intellectual assets and to allocate property rights among innovation stakeholders (Teece 1986). Scholars have acknowledged that innovative firms try to evaluate the appropriability of innovation early in the invention phase; such an appropriation strategy becomes critical when firms aim to protect their market positions (Milesi et al. 2013).

This representation of the innovation process is interesting for our purposes, as it can be applied to describing a business ecosystem's lifecycle, which according to Moore ( 1993 ) is comprised of four phases: birth, expansion, leadership, and regeneration (renewal). The birth phase involves the realization of activities that correspond to the different stages of the invention phase. The birth of an ecosystem is thus defined as a period of "ideation" during which "visionaries... form embryonic ecosystems" (Moore 1996, p. 70). During this period, an innovative firm attempts to establish a "proof of concept" (Moore 2006) that is likely to offer an alternative to existing services and goods, or to open up a new market and generate value. During the ideation stage, describing the value that will be provided to customers is not the only objective. Through "value chaining" (Moore 1996), actors also develop dynamic competencies, thereby facilitating the combination or connection of distributed resources. The aim is then to identify a space of opportunity justifying the recombination or reorganization of firms' resources and competencies. A firm and its partners attempt to position themselves within a more or less structured market based on the technological maturity of their assets. Actors also seek to evaluate whether customers' needs are real, latent, or emergent, and whether the regulatory environment requires the development of norms, rules, and standards conducive to ecosystem development.

Similar to the invention phase of the innovation process, the birth of an ecosystem is also decomposable into four stages: (a) presenting new ideas for developing value-creating relationships, (b) taking action and experimenting, (c) creating value for customers and investors, and (d) thinking reflectively about what has been created (Moore 1996). During the first stage, members of the ecosystem seek to identify which competitive advantage to build. Then, during the second stage, actors identify a primitive offer and determine a targeted population of customers. During the third stage, actors expand their architecture by inviting new members to enter the ecosystem in order to access assets and processes that are necessary for the development of the value proposition. Finally, during the fourth stage, actors evaluate past actions through reflexive analysis, and look forward so as to anticipate future needs and prepare 
themselves for the subsequent phases of the ecosystem's lifecycle (expansion and leadership).

While the first three stages of the birth phase correspond to the stages of the invention phase, the expansion and leadership phases correspond more closely to the commercialization phase of the innovation process. Indeed, during the expansion phase, actors combine their resources and competencies in order to increase the value and performance of the ecosystem. The objective is to work with suppliers and partners in order to develop economies of scale and to extend the commercial offer generated by the new ecosystem by diffusing the business concept on which it was built (Moore 1993). This phase is further characterized by risks associated with strategic conflicts between members, such as those commonly observed in the high technology sector (e.g., standards wars). Early identification of such problems is essential, especially when an actor in the ecosystem does not have the necessary resources to fulfill its role, which can constrain an ecosystem's developmental progress (Moore 1996). Stabilizing and achieving a critical mass of stakeholders constitute the main challenge of the expansion phase. As in the commercialization phase of the innovation process, appropriation strategies play a key role during the expansion and leadership phases. These strategies may depend on legal (e.g., intellectual property right, patents, etc.) or strategic mechanisms (Milesi et al. 2013), but their objectives are to ensure the stability of the ecosystem's business model (Moore 1996). Once stability is achieved, members can adopt long-term strategies (Nambisan and Baron 2013). Lastly, in order to maintain stability during the regeneration phase, and to avoid decline, the ecosystem must be continuously improved, and actors must engage in new innovation processes.

Table 1 presents the lifecycle of a business ecosystem considered as an innovation process. It establishes a correspondence between the invention and commercialization phases of innovation, and the phases of a business ecosystem's lifecycle.

\section{Table 1}

Phases of the innovation process and the business ecosystem lifecycle

\begin{tabular}{|l|l|l|l|l|}
\hline \multicolumn{2}{|c|}{ Innovation process } & \multicolumn{2}{c|}{ Lifecycle of a business ecosystem } \\
\hline \multicolumn{1}{|c|}{ Phases } & \multicolumn{1}{|c|}{ Stages } & Phases & \multicolumn{2}{c|}{ Stages } \\
\hline & Ideation & & Research \\
\hline Invention & Conception & Birth & $\begin{array}{l}\text { Action and } \\
\text { experimentation }\end{array}$ & Retroaction \\
& Translation & & Value creation & \\
\hline & & & \\
\hline
\end{tabular}




\begin{tabular}{|l|l|l|l|}
\hline & $\begin{array}{l}\text { Identification of } \\
\text { customers } \\
\text { needs }\end{array}$ & Expansion & $\begin{array}{l}\text { Development of economies of } \\
\text { scale }\end{array}$ \\
\cline { 3 - 4 } & $\begin{array}{l}\text { Creation of a } \\
\text { value chain }\end{array}$ & & $\begin{array}{l}\text { Mitigation of conflicts } \\
\text { between members }\end{array}$ \\
\hline & Appropriation & Leadership & $\begin{array}{l}\text { Appropriation } \\
\text { Creation of long term } \\
\text { strategies }\end{array}$ \\
\hline- & Regeneration & Continuous improvement \\
\hline
\end{tabular}

\section{Innovation Capacity and Knowledge Process Management}

If the development of a business ecosystem is similar to an innovation process, it requires members to have mastered skills and competencies required for the realization of knowledge-intensive tasks and activities. These skills and competencies comprise a firm's innovation capacity. According to Wang and Ahmed (2007), a firm's innovation capacity is comprised of three organizational abilities corresponding to the different phases of the innovation process: the ability to identify and capitalize on market opportunities during the ideation stage of the invention phase; the ability to recognize the value creation potential of external resources, assimilate these resources, and apply them for commercial purposes during the conceptualization and translation stages of the invention phase; and the ability to develop new markets for innovative products and services during the commercialization phase. Similarly, Burgelman et al. (2004) considered a firm's innovation capacity to stem from two elementary competences: (a) design competence for tasks such as resource planning and allocation, which are critical during the invention phase; and (b) realization competence, for tasks related to the organization and commercialization of the innovation. Teece (2007, p. 1339) also acknowledged that "the ability to integrate and combine assets including knowledge is a core skill." Building on this framework, Michailova and Zhan (2015, p. 576) used the term dynamic knowledge capacity to reflect the generative and integrative nature of a firm's innovation capacity.

The foregoing stresses the importance of knowledge management practices for innovative firms. Scholars have shown that a positive relationship exists between knowledge management and a firm's innovation capacity: "Knowledge management helps to develop skills through capability enhancement by the acquisition, transfer, dissemination and application of accumulated knowledge" (Jyoti et al. 2011, p. 327). According to Cepeda and Vera (2007), knowledge management processes and innovation capacity are closely linked, because the 
latter, which is considered to be a dynamic capability, "requires experience accumulation and knowledge articulation and codification" (Cepeda and Vera 2007 , p. 427). In addition, a variety of knowledge processes are involved in the acquisition of innovation capacity, and by extension, the development of innovation. For example, Jyoti et al. (2011) identified seven knowledge management processes that shape innovation capacity: knowledge sharing and formalization; knowledge creation and protection; and knowledge transformation, use, and acquisition (Jyoti et al. 2011). Gebauer et al. (2012) also suggested that innovation depends on firms' absorptive capacity, which is influenced by the interaction between firms' learning and knowledge combination processes.

While the relationship between knowledge and innovation management has drawn significant research attention, very few researchers have focused on the role played by knowledge management processes in the development of business ecosystems (with the exception of Attour and Ayerbe 2012). Few have attempted to characterize competencies deployed by actors during the birth phase of a business ecosystem. For example, Loilier and Malherbe (2012, 2013) showed that during the birth of an ecosystem, transitions from one stage to the next are facilitated by a combination of three types of competencies: technical competencies required to develop innovation, relational competencies required to establish connections among participants in the ecosystem, and commercial competencies required to structure a marketable service offering (Loilier and Malherbe 2013).

Loilier and Malherbe's $(2012,2013)$ works are helpful in the analysis of a business ecosystem's birth phase. However, their works are limited to a single phase, and they did not study which knowledge processes contribute to the development of competencies throughout an ecosystem. In this paper, we consider a business ecosystem to be a unique collaborative organizational form that supports the invention and commercialization of new products and services. Within this framework, understanding how a business ecosystem emerges and evolves requires exploring the nature and logics of the knowledge processes that its members deploy during the different phases of its lifecycle.

\section{Methodology and Presentation of the Case Study}

We adopted a qualitative case study methodology (Stake 1995) to explore how business ecosystems emerge and develop (3.1). Specifically, we performed a unique case study of the development of a near-field communication platform (Gawer 2014), the Sophia-Zen project (3.2). 


\section{An Exploratory Approach Whereby Data Are Collected} Through Active Observation

We used an exploratory approach (Yin 1989) to develop the case study. Like any other qualitative research based on a single case study, generalization of results could be called into question. To fill this lack, the case study has to be driven "as if we built and updated gradually a network of rules and more or less contextual exceptions" (David 2004, p. 6). Therein, Geertz (1973) called for carrying a "thick description," i.e., a rich set of details idiosyncratic to the context of the studied case. Thick description provides the necessary data to evaluate the generalization of single case study through the question of the transferability of its results to another case (Guba and Lincoln 1994; Ayerbe and Missonier, 2007). Following Geertz ( 1973 ), data were collected by active observation. Collecting data through active observation enables a researcher to investigate a poorly known phenomenon in its natural context (David 2000); moreover, observing in situ helps researchers contextualize un(der)studied phenomena within the existing literature. One of the authors of this paper benefited from researcher-observer status known by all actors of the Sophia-Zen project. She adopted a fixed position of continuous daily observation of real situations throughout all phases of the case study. Active observation enabled us to systematically and exhaustively collect rich primary data without deliberately disrupting the studied phenomena (Savall and Zardet 2004). She collected primary data as participants in various meetings (face-to-face, telephone, or Visio-conference) which enabled us to follow how the Sophia-Zen business ecosystem was set-up and evolved through various phases of development. This primary source of data was complemented by secondary data in the form of technical documents provided by practitioners, project annual reports, and information available online about similar projects in which one or more actors in our case study participated. Inductive thematic analysis of this copious information (Paillé 1996 ) led us to identify three broader themes: business ecosystems, open innovation, and knowledge management processes.

More precisely, several round trips between her field observation and the theory were necessary to favor the interpretation, validation, and reformulation of hypotheses by repeated confrontations of observations and theory. We first built hypotheses from an analysis of the literature that were tested in field situations and/or in the business ecosystem literature by gathering data. These hypotheses focused on how an ecosystem emerges and develops and on which knowledge processes are necessary in any collaborative innovation. Here, deductive reasoning led us to identify which knowledge processes were mobilized by Sophia-Zen members all along the phases of their ecosystem's lifecycle. Then, field observations enabled a number of assumptions regarding how these 
processes get linked together to shape Sophia-Zen lifecycle. These assumptions were then tested both in the literature and the field context in which the author was immersed in order to form patterns about which knowledge processes are involved in the birth, expansion, leadership, and renewal phases of a business ecosystem.

\section{The Sophia-Zen Project}

The actors in the Sophia-Zen project were as follows: GFI Informatique (GFI), an international IT services group; the University of Nice-Sophia Antipolis (UNS); Envibus, the public transportation network of Sophia Antipolis; and the local government, Communauté d'Agglomération de Sophia Antipolis (CASA). Sophia-Zen embodies two technical solutions deployed respectively by UNS and GFI. The first solution called CHEMIN ${ }^{1}$ is a mobile near-field communication (NFC) platform developed by UNS that provides self-guided tour information. CHEMIN couples two services:

- A multimedia information service (videos, audios, and photos provided by the local government) delivered via mobile phone that provides information to people engaged in cultural, historical, or community tours.

- A geo-positioning service delivered via mobile phone that provides information (videos, audios, photos, or comments) about the places people are moving through in real time based on a border system created by NFC tags placed in key local places.

Through these two services, CHEMIN also enables the local government (CASA) to announce specific events or information.

The second solution is called ENTREPRISE and was deployed by the IT service group (GFI). The technology, which is targeted at companies in the Sophia Antipolis economic area, provides users with two services:

- The "I am lost" service is based on a geo-positioning system similar to the world global positioning system (GPS), but specific to the Sophia Antipolis region. The purpose is to resolve issues related to the lack of information and precision of the world GPS, which often does not provide the exact searched position or cannot find the searched place. This system also updates Sophia Antipolis companies' positions (e.g., when a company moves within the technology park) thanks to data provided to the IT service group (GFI) by the local government;

- The "I move" service is a dynamic carpooling system which enables Sophia 
Antipolis employees and students to communicate in real time and to facilitate ride sharing. "I move" allows shows real-time bus schedules and notifies travelers of possible bus delays or traffic congestion.

Through these two services, ENTREPRISE also enables companies in the Sophia Antipolis region to announce specific events (i.e., workshops, seminars, meetings, etc.). To summarize, Sophia-Zen is a multisided platform (Rochet and Tirole 2006) that connects three groups of people (see Fig. 1):

Fig. 1

The Sophia-Zen platform

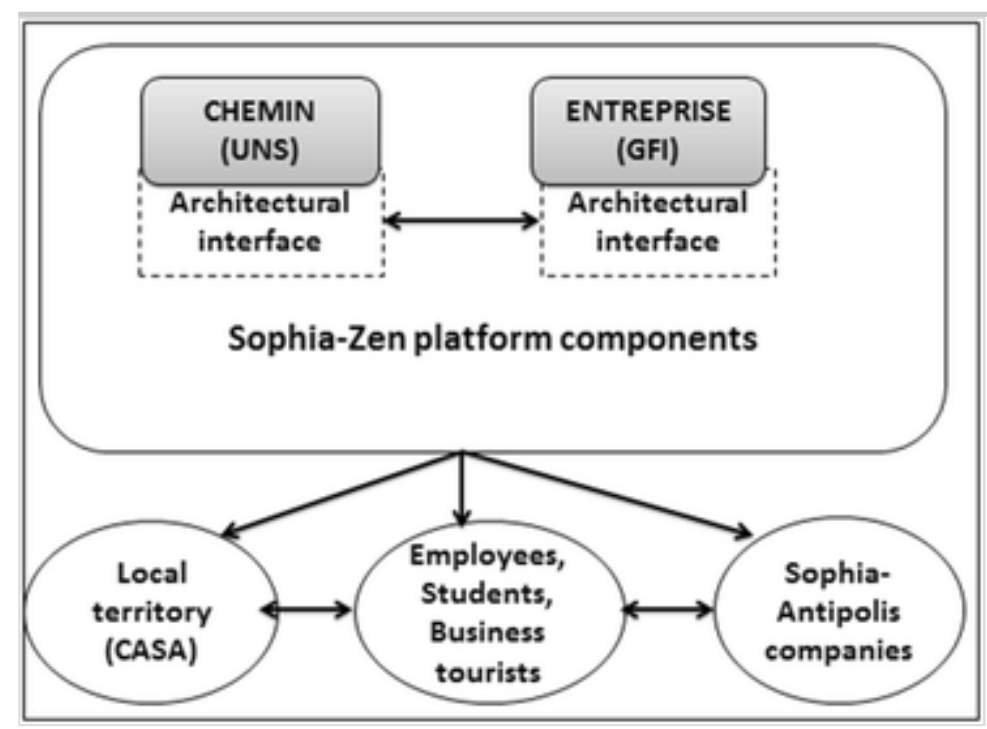

- Employees, students, or business tourists moving within the region;

- Employees, students, or business tourists interacting for transportation reasons; and

- Employees, students, or business tourists interacting with Sophia Antipolis companies for business reasons.

\section{Results}

In this section, we present the findings of the case study. Specifically, we identify and discuss the knowledge processes associated with the various phases of Sophia-Zen's lifecycle (Moore 1993, 1996).

\section{Sophia-Zen's Birth: a Combination of Knowledge Creation and Alignment Processes}

Sophia-Zen's birth phase began with a brainstorming session involving members of UNS's master of computer science, networking, database, and systems 
integration (MBDS) $)^{2}$ research team (three project managers and a scientific leader). During this ideation stage, MBDS team members sought to identify the best way to respond to a call for experimental projects (PacaLabs) published in 2010 by the Provence-Alpes-Côte-d'Azur (PACA) regional council. The scientific leader invited the project managers who had deployed a prior version of the CHEMIN platform to meet in order to discuss the possibility of combining and improving the outcomes of prior implementations in Nice, Menton, and Grasse. This tacit-collective knowledge exchange was facilitated by individuals sharing common beliefs and development routines for web interfaces and NFC applications. This sharing of tacit-collective knowledge led to the generation of ideas that could be exploited to advance the Sophia-Zen project, specifically those related to unifying different versions of the CHEMIN platform and enriching it by adding a geo-positioning service in order to solve traffic congestion problems within the Sophia Antipolis technology park.

During the second stage, project managers experimented with this idea. Building on their tacit-explicit collective knowledge, they first mapped out all deployed functions in prior versions of CHEMIN to identify what changes to the old versions of the platform were required and achievable on the one hand, and to align formal rules and procedures inherited from prior versions on the other hand. In addition, project managers used other explicit-collective knowledge based on reviews of existing studies and applications of scientific principles and methods (Asheim 2005). In doing so, they defined concepts that should be developed specifically for the Sophia-Zen project, in particular, the platform technical architecture and its web interface and use cases (e.g., NFC terminal management, media management, CHEMIN path management, etc.). AQ2

Project managers worked on these concepts with the scientific leader, stressing the necessity of developing a unique version of CHEMIN in order to solve inherited problems and incrementally enhance existing functionalities by integrating new technologies (e.g., by upgrading the Google Maps API from version 1 to version $3,{ }^{3}$ integrating mobile applications for the Android platform, etc.). The internalization of these concepts had been fostered by the team's tacit knowledge of what to do. So, to legitimate the new architecture of the CHEMIN platform, the team mobilized this knowledge. In this step, dialogue with GFI was essential. Indeed, the IT service group's (GFI) entrance in Sophia-Zen innovation process generated a new knowledge loop or spiral (in sense of Nonaka 1994) that enabled the actors to learn by dialoguing and discussing strategies for sharing knowledge (tacit and explicit) so as to combine CHEMIN with ENTREPRISE (two explicit forms of knowledge). 
This new knowledge generation cycle led to the formulation of novel concepts for the Sophia-Zen project. It essentially involved knowledge concerning CHEMIN and ENTREPRISE functionalities and how to connect them. The challenge was formalizing how to coordinate, align, and integrate the uses and organizational routines embedded in each component. Knowledge sharing was realized through several communication channels: a brainstorming session, two meetings between the university (UNS) and the IT service group teams, and several email exchanges. Knowledge exchanges during this stage built on existing technical competencies related to Sophia-Zen's existing components from prior projects. Together with the shared beliefs about the innovation context, these competencies made it possible to explore market opportunities (i.e., dynamic carpooling) that would require using one or several components of the CHEMIN and/or ENTREPRISE services.

\section{Expansion Phase: Knowledge Recombination and Alignment}

The combination of explicit knowledge that occurred during the expansion phase was rooted in incremental improvements to and interconnections among university's and the IT service group's (GFI) respective components. The translation of the concept into an operational artifact proceeded in two steps. First, the actors transformed and recombined prior knowledge to develop their own components. For university, the aim was to merge previous versions and improve components of the CHEMIN platform (either to resolve technical problems or to innovate) and to add new functionalities (see Table 2).

\section{Table 2}

Transformation and recombination of CHEMIN by UNS

\section{Transformation of existing components}

New architecture for the administrative web site Updated statistics collection format (NFC tags)

\section{Development of new components}

Web services for mobile applications Ability to post user comments Improved user experience

- Option to link to extra information based on the destination address

- Option to create automatic routes/itineraries

For the IT service group (GFI), the challenge was to make the Transports Public Genevois ${ }^{4}$ (TPG) app interoperable and to enrich it by adding new functionalities (see Table 3 ). Notably, university students on internship placements or apprenticeship contracts with GFI developed these new functionalities. 
Table 3

Transformation and recombination of ENTREPRISE by GFI

AQ3

Transformation of existing components

Render the Transports Publics Genevois (TPG) app interoperable

- Enable the development of a geo-localization solution and multimodal guidance for dynamic carpooling

Make the TPG app compatible with the Android operating system

\section{Development of new components}

Add two functionalities to improve the user experience

- Option to link to extra information based on the destination address

- Option to create automatic routes/itineraries

Create a GPS dedicated to Sophia

Antipolis companies

- Enable geographic positions to be updated

Develop applications

- "I am lost" which provides routes

- "I move" which enables

employees to communicate for carpooling purposes

Second, connecting Sophia-Zen's components (CHEMIN and ENTREPRISE) required a mutual assimilation (absorption) of new knowledge created by the university (UNS) and the IT service group (GFI) as they updated and transformed their own components. This step triggered the redefinition of each component's technical architecture. From this perspective, actors mobilized the architectural knowledge embedded in their own components. For example, some developments were made by the university to define CHEMIN as an open source platform. This strategic choice differed from the one adopted by GFI, which had an appropriation strategy based on a proprietary regime. Consequently, protecting knowledge exchanges between the university and the IT service group required adopting an alternate solution that enabled Sophia-Zen components to be connected without subjecting the IT service group to an open source regime. For that purpose, actors developed relational competencies that enabled them to mitigate strategic conflicts between the actors.

\section{From Expansion to Maturity: Knowledge Valorization and Protection}

How knowledge was to be applied had been defined in the cooperative agreement negotiated during the birth phase and implemented during the maturity phase. Participants in the Sophia-Zen project began by clarifying conditions of knowledge exchange and protection among the various stakeholders. Regarding background knowledge, it had been agreed that "each party retains the exclusive rights to its background knowledge, IPR [intellectual property rights] and know-how related to this knowledge." 5 An informative (but 
non-exhaustive) list of background knowledge had been established for that purpose, and as indicated in the cooperative agreement, the list could be updated depending on how the project advanced. This list was necessary, since during project conceptualization, the use of background knowledge constituted by open source software or owned under an open source license implied that all or parts of the research findings must be licensed under an open source license. Yet, as stated above, this contradicts the appropriation regime adopted by the IT service group (GFI) for ENTREPRISE.

Furthermore, the use of background knowledge for exploitation purposes was subject to a prior agreement between the two parties. As patents are critical knowledge management tools within collaborative innovation projects (Pénin et al. 2013), the cooperative agreement anticipated the possibility of conferring a nonexclusive, non-transferable license without sublicensing rights for the use of necessary background knowledge to achieve the objectives of the project. Because of this restrictive clause, CHEMIN and ENTREPRISE were developed independently. No explicit background knowledge of the university (UNS) was mobilized in the conception of the IT service group's component, and vice versa. Only tacit knowledge was exchanged between the actors, in particular, the "know-how" accumulated and transferred through UNS students placed at GFI as interns and apprentices. This type of tacit knowledge, closely linked to the conceptualization stage, is not patentable. Finally, considering major differences in actors' strategic positions and exploitation constraints (due to obligations to license the use of background knowledge), the technical architectures of both CHEMIN and ENTREPRISE evolved during the expansion phase. Two independent technical interfaces, with opposite properties (open source for UNS, licenses for GFI), co-evolved henceforth during the maturity phase.

Arrangements for the exploitation of results also motivated the IT service group to favor the new architecture of the Sophia-Zen project (an architecture that separates the technical architectures of CHEMIN and ENTREPRISE). Indeed, the cooperative agreement anticipated that each actor could freely exploit its own project results (i.e., knowledge) that had not been exploited collectively, as well as common results developed during the project with property appropriation. Each actor had free, but not exclusive rights to use the results owned by the other for the project and R\&D needs, excluding any industrial or commercial activity. To conclude, in the cooperative agreement, each actor had committed to grant (upon written request) a license permitting the use of its own results or the results of the collaborative project with property appropriation for exploitation purposes under equal, reasonable, and nondiscriminatory conditions.

\section{Discussion}


Performing the Sophia-Zen case study enabled us to map knowledge management processes associated with the different phases of a business ecosystem's lifecycle. Specifically, the case study highlights the roles played by three types of knowledge processes: generation, application, and valorization. Together, these knowledge processes enable the performance of several tasks and activities associated with a business ecosystem's lifecycle, which is considered to be a specific type of innovation process.

\section{The Generation of Knowledge}

Knowledge generation processes are essential to the development of a business ecosystem. In the case of the Sophia-Zen platform, knowledge generation proceeds through the recombination and integration of knowledge in order to develop a service offering that is likely to create value for customers. The generation of knowledge relies on a dynamic capacity that transforms stakeholders' tangible and intangible assets, the latter being distributed (at least initially). During an ecosystem's birth phase, evidence from our case study shows that new knowledge is "created and converted into products, services and processes by transforming general knowledge into specific knowledge" (LopezNicolas and Merono-Cerdan 2011, p. 504). Within this framework, actors' absorptive capacity (Cohen and Levinthal 1990) plays a key role.

Wang and Ahmed (2007) showed that a firm's dynamic capabilities are supported by four types of knowledge processes: integration, reconfiguration, renewal, and recreation. Verona and Ravasi (2003) also suggested that a firm's dynamic capacities are fundamentally anchored in the creation, absorption, integration, and reconfiguration of knowledge. These processes are at the core of the invention phase, which constitutes "the driving force behind the creation of new products" (Verona and Ravasi 2003, p. 579).

In our case study, absorption capacity enabled stakeholders to link the different stages of the invention phase (ideation, conception, and translation) constituting the birth of the ecosystem. Initially dependent on actors' accumulated background knowledge (Noblet and Simon 2010), the generation of new knowledge is based on actors' abilities to recognize, valorize, and acquire external information - skills that are essential to operational realization (Zahra and George 2002). The assimilation of external knowledge provided a rationale for initial interactions. The foregoing contributed to tacit and explicit knowledge transformation through the internalization and recombination of acquired knowledge.

\section{The Application of Knowledge}


Located at the interface between the birth and expansion phases of the ecosystem, knowledge application processes enable the combination of individually or collectively generated knowledge held by project stakeholders, and its incorporation into new products and services. Knowledge application processes critically depend on the balance between knowledge combination and sharing on the one hand, and knowledge control on the other hand.

During the expansion phase of the ecosystem, relational competencies enabling interactions between actors facilitated the sharing and combination of internal knowledge processes that informed the collaborative design of Sophia-Zen platform. Within each organization, knowledge management practices relied principally upon knowledge generation. However, collective knowledge management processes required tradeoffs between knowledge sharing and protection. Here, the alignment of internal and external, individual, and collective knowledge played a decisive role. This alignment depended heavily upon how architectural knowledge was incorporated into the platform: first, the university's internal knowledge processes largely determined the ecosystem's components and the linkages between them; then, the components (both technical and nontechnical) were aligned collaboratively during the different project phases. Therefore, knowledge alignment processes played a central role during the transition between the birth and the expansion phases of the ecosystem's lifecycle. ${ }^{6}$

In cases of inter-organizational innovation such as Sophia-Zen, links between modularized knowledge components are established through collective action between two or more actors benefiting from different market positions. This design task depends upon two imperatives: the development of communication channels and filters between actors on the one hand, and the instantiation of four prior architectural knowledge dimensions on the other hand-namely, technology awareness, use context sensitivity, business model understanding, and boundary-spanning competence (Andersson et al. 2008). These four dimensions enable the analysis of inter-organizational innovation processes and are fundamental to creating spaces of exchange in which actors meet and negotiate to align their knowledge and technologies (cf. Kellogg et al. 2006).

By extension, it is necessary to protect the partners who are engaged in these exchanges. In the Sophia-Zen case, the transitions from the birth phase to the expansion phase and from the expansion phase to the maturity phase were closely linked to the appropriation strategy adopted by the members of the ecosystem. 


\section{The Valorization of Knowledge}

The valorization of knowledge involves the deployment of knowledge management strategies aimed at protecting intangible assets deployed by actors and appropriating the value generated through the commercialization of innovation. Our case study findings indicate that during all phases of innovation, the conditions of collaboration among different stakeholders must be clarified. Knowledge protection issues, such as the intellectual property rights (IPR) to the knowledge exchanged between partners, were critically important to project stakeholders.

Similarly, because the Sophia-Zen project required the generation of new knowledge through the synthesis and transformation of actors' internal background knowledge, the challenges and issues regarding knowledge protection focused not only on newly created knowledge but also on what Gassmann and Bader (2006) called "foreground" and "sideground" knowledge. In a proposed typology of IPR, the authors distinguished three types of knowledge: knowledge developed before collaboration (background); knowledge resulting from collaboration (foreground); and knowledge developed by each actor during the innovation process, but not as a result of collaboration (sideground). This typology helps partners protect the knowledge developed outside the collaboration on the one hand, and share the knowledge resulting from the collaboration on the other hand.

These issues were central to the Sophia-Zen project. Our results suggest that the main partners of the project adopted opposite appropriation strategies, justifying the execution of a cooperative agreement in order to define the modalities of IPR management associated with the exploitation of different types of knowledge (i.e., background, foreground, sideground).

\section{Linking Knowledge Processes}

Beyond process typologies and knowledge types, our case study provides insights regarding how knowledge processes are linked together during a business ecosystem's lifecycle. The resulting framework has three main implications (Fig. 2).

\section{Fig. 2}

Knowledge dynamics and a business ecosystem's lifecycle 


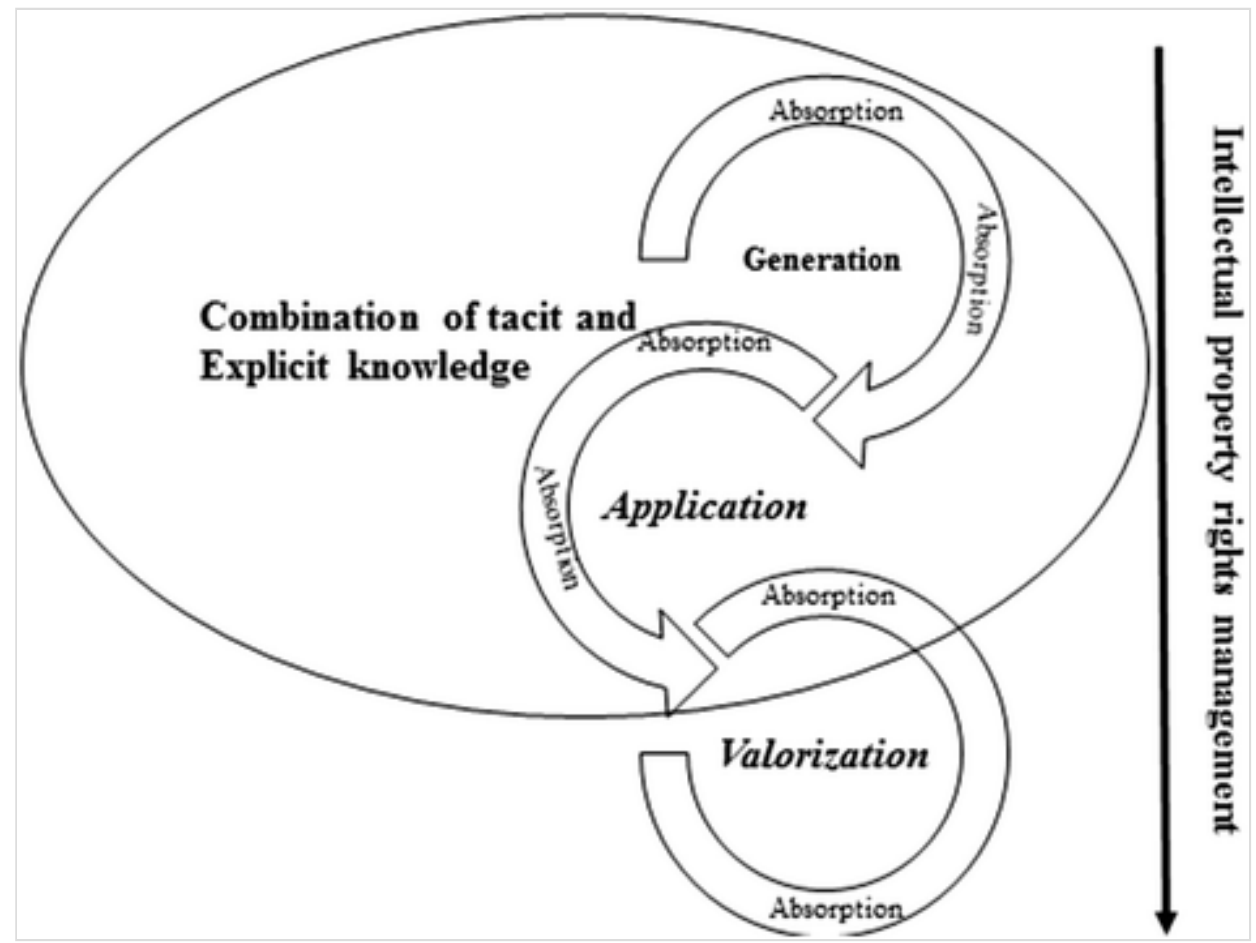

AQ4

First, it shows that knowledge absorption processes are not limited to the upstream phases of the cycle, but play a role during transitions from one phase to another. They also facilitate the coordination of - and transitions betweenknowledge generation, application, and valorization processes. In particular, absorption processes foster knowledge generation and application within interorganizational innovation contexts.

Second, evidence is provided that the development of an ecosystem is tightly coupled with the transformation of individual and collective-tacit knowledge into collective-explicit knowledge. These transformational dynamics are observed during all phases of an ecosystem's lifecycle, and within each knowledge process, particularly knowledge generation and application.

Finally, evidence suggests that IPR management shapes the transformational dynamics along the various phases of the lifecycle, from upstream (invention) to downstream (commercialization) phases of the innovation process.

\section{Conclusion}

This contribution elaborated on a framework for studying business ecosystems lifecycle by focusing on knowledge types and processes used by the various stakeholders. Despite significant advances in the literature, only fragmented knowledge exists about the nature and logics of knowledge processes supporting the various phases of business ecosystems' development. As Corbel and Simoni (2012, p. 71) argued, this fragmentation exists because the "innovation management literature and works on knowledge management have, at least 
partly, developed separately."7 Considering that the development of a business ecosystem requires innovation capacities supported by the combination of knowledge management processes (i.e., generation, application, and valorization), we explicitly linked together separated literatures, namely knowledge management, management of innovation, and business ecosystems. Drawing on case study evidence, we identified three classes of knowledge processes supporting the different phases of a business ecosystem's lifecycle, the later being considered as a typical case of collaborative innovation (Barbaroux and Attour 2016).

The proposed framework must be viewed as the result of exploratory research aimed at improving our understanding of the knowledge processes operating throughout different phases of a business ecosystem's lifecycle. Additional research is required to evaluate the empirical validity and theoretical relevance of the knowledge dynamics depicted in Fig. 2. An interesting avenue for future research would be to investigate the knowledge dynamics supporting the development of innovation in other organizational forms, such as communitybased innovation (innovation as a community of communities), open innovation, or crowdsourcing.

\section{References}

Aarikka-Stenroos, L., Sandberg, B., \& Lehtimäki, T. (2014). Networks for the commercialization of innovations: a review of how divergent network actors contribute. Industrial Marketing Management, 43, 365-381.

Amin, A., \& Cohendet, P. (2004). Architecture of knowledge. Firms, capabilities and communities. Oxford: Oxford University Press.

Andersson, M., Lindgren, R., \& Henfridsson, O. (2008). Architectural knowledge in organizational IT innovation. The Journal of Strategic Information Systems, 17(1), 19-38.

Arthur, W. B. (2007). The structure of invention. Research Policy, 36, $274-$ 287.

Attour, A., \& Ayerbe, C. (2012). Connaissances et innovation au sein des écosystèmes d'affaires. Le cas des services mobiles. Revue Française de Gestion, 221, 77-94.

Attour, A., \& Ayerbe, C. (2015). Le management amont et aval des droits de 
propriété intellectuelle au sein des écosystèmes-plateformes naissants. Système d'Information et Management, 20(3), 47-96.

Attour, A., \& Barbaroux, P. (2016). Architectural knowledge and the birth of a platform ecosystem. Innovations Journal of Innovation Economics and Management, 2016/1(19), 11-30.

Attour, A. \& Della Peruta, M. (2014). Architectural knowledge: key flows and processes in designing an inter-organizational technological platform. Knowledge Management Research \& Practice. Advance online publication 4 August 2014; doi: 10.1057/kmrp.2014.21

Ayerbe, C., \& Missonier, A. (2007). Validité interne et validité externe de l'étude de cas: principes et mise en œuvre pour un renforcement mutuel. Finance Contrôle Stratégie, 10(2), 37-62.

Barbaroux, P. (2014). Rupture technologique et naissance d'un écosystème: voyage aux origines de l'internet. Revue d'Économie Industrielle, 146(2), 2759 .

Barbaroux, P., \& Attour, A. (2016). Interactive approaches to innovation and kowledge management. Innovations Journal of Innovation Economics and Management, 2016/1(19), 3-10.

Burgelman, R. A., Maidique, M., \& Wheelright, S. (2004). Strategic management of technology and innovation. New York: McGraw-Hill.

Cepeda, G., \& Vera, D. (2007). Dynamic capabilities and operational capabilities: a knowledge management perspective. Journal of Business Research, 60, 426-437.

Clarysse, B., Wrigt, M., Bruneel, J., \& Mahajan, A. (2014). Creating value in ecosystems: crossing the chasm between knowledge and business ecosystems. Research Policy, 43, 1164-1176.

Cohen, W., \& Levinthal, D. (1990). Absorptive capacity: a new perspective on learning and innovation. Administrative Science Quarterly, 35, 128-152.

Corbel, P., \& Simoni, G. (2012). Innovation et partage des connaissances. Revue Française de Gestion, 221, 71-75.

David, A. (2000). Logique, épistémologie et méthodologie en sciences de 
gestion: Trois hypothèses revisitées. In A. David, A. Hatchuel, \& R. Laufer (Eds.), Les nouvelles fondations des sciences de gestion - Eléments d'épistémologie de la recherche en management (pp. 83-110). Paris: Vuibert.

David, A. (2004). Etudes de cas et généralisation scientifique en sciences de gestion. Le Havre: Actes de la XIIIème Conférence de l'Association Internationale de Management Scientifique.

Fidel, P., Schlesinger, W., \& Cervera, A. (2015). Collaborating to innovate: effects on customer knowledge management and performance. Journal of Business Research, 68, 1426-1428.

Gassmann, O., \& Bader, M. A. (2006). Intellectual property management in inter-firm R\&D collaborations. Taiwan Academy of Management Journal, 6(2), 217-236.

Gawer, A. (2014). Bridging differing perspectives on technological platforms: toward an integrative framework. Research Policy, 43, 1239-1249.

Gebauer, H., Worch, H., \& Truffer, B. (2012). Absorptive capacity, learning processes, and combinative capabilities as determinants of strategic innovation. European Management Journal, 31(1), 57-73.

Geertz, C. (1973). Thick description: toward an interpretative theory of culture. In C. Geertz (Ed.), The interpretation of cultures (pp. 3-30). NewYork: Bas Books.

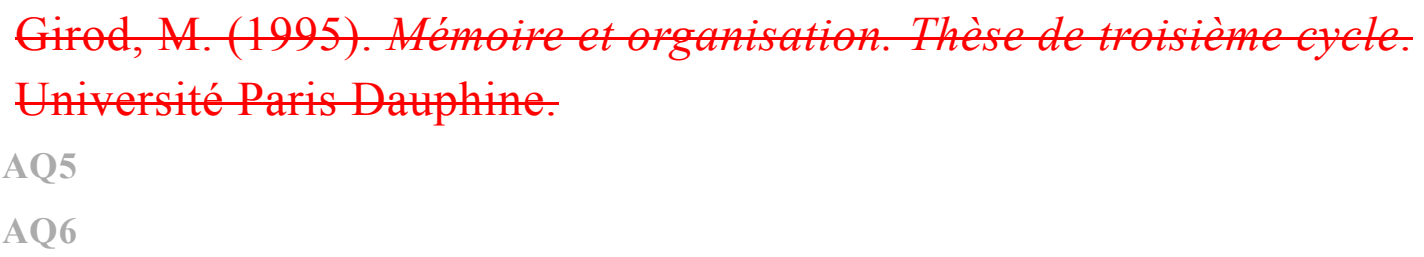

Guba, G. \& Lincoln, Y.S. (1994). Competiting paradigms in qualitative research. In N.K. Denzin et Y.S. Lincoln (Eds). On the Book of Qualitative Research, Sage, 105-117.

Iskia, T., Lescop, D. Lescop, E. (2014). An evolutionary view of platformbased ecosystems. Colloque GECSO-7ème Conférence sur le Gestion des Connaissances dans la Société et les Organisations (GeCSO) 2014. 4 \& 5 juin 2014. Aix-en-Provence, France 
Jyoti, J., Gupta, P., \& Kotwal, S. (2011). Impact of knowledge management practices on innovative capacity: a study of telecommunication sector. Vision, 15(4), 315-330.

Kellogg, K., Orlikowski, W., \& Yates, J. (2006). Life in the trading zone: structuring coordination across boundaries in postbureaucratic organizations. Organization Science, 17(1), 22-44.

Kline, N., \& Rosenberg, N. (1986). An overview of the process of innovation. In G. Landau \& N. Rosenberg (Eds.), The positive sum strategy: harnessing technology for economic growth (pp. 275-306). National Academies Press: Washington, DC.

Koenig, G. (2013). Business ecosystem revisited. In S. Ben Letaifa (Ed.), Understanding business ecosystems (pp. 69-84). Paris: De Boeck.

Lema, R., Quadros, R., \& Schmitz, H. (2015). Reorganising global value chains and building innovation capabilities. Research Policy, 44, 1376-1386.

Loilier, T., \& Malherbe, M. (2012). Le développement des compétences éco systémiques. Le cas de l'ESA émergent des services mobiles sans contact. Revue Française de Gestion, 222, 89-105.

Loilier, T., \& Malherbe, M. (2013). Experimentation and the development of eco-systemic competencies in the field of contactless mobile services. In $\mathrm{S}$. Ben Letaifa (Ed.), Understanding business ecosystems (pp. 193-207). Paris: De Boeck.

Lopez-Nicolas, C., \& Merono-Cerdan, A. L. (2011). Strategic knowledge management, innovation and performance. International Journal of Information Management, 31, 502-509.

Michailova, S., \& Zhan, W. (2015). Dynamic capabilities and innovation in MNC subsidiaries. Journal of World Business, 50, 576-583.

Milesi, D., Petelski, N., \& Verre, V. (2013). Innovation and appropriation mechanisms: evidence from Argentine microdata. Technovation, 33, 78-87.

Moore, J. (1993). Predators and prey: a new ecology of competition. Harvard Business Review, 71(3), 75-86.

Moore, J. (1996). The death of competition-leadership and strategy in the 
age of business ecosystems. Harper Business. Brownstown: From Motor City Books

Moore, J. (2006). Business ecosystems and the view from the firm. The Antitrust Bulletin, 51(1), 31-75.

Nambisan, S., \& Baron, R. A. (2013). Entrepreneurship in innovation ecosystems: entrepreneurs' self-regulatory processes and their implications for new venture success. Entrepreneurship Theory \& Practice, 37(5), 10711097.

Noblet, J. P., \& Simon, E. (2010). Capacité d'absorption: revue de littérature, opérationnalisation et exploration. Gestion, 27(6), 59-74. 2000.

Nonaka, I. (1994). A dynamic theory of organizational knowledge creation. Organization Science, 5(1), 14-37.

Paillé, P. (1996). De l'analyse qualitative en général et de l'analyse thématique en particulier. Recherches Qualitatives, 15, 179-194.

Palmberg, C. (2006). The sources and success of innovations. Determinants of commercialization and break-even times. Technovation, 26, 1253-1267.

Pénin, J., Burger-Helmchen, T., Dintrich, A., Guittard, C., \& Schenk, E. (2013). L'innovation ouverte. Définition, partiques et perspectives, prospectives et entreprise: Eclaireg sur les entreprises dans un monde ouvert. Paris: CCI.

Reich, B. H., Gemino, A., \& Sauer, C. (2014). How knowledge management impacts performance in projects: an empirical study. International Journal of Project Management, 32, 590-602.

Rochet, J. C., \& Tirole, J. (2006). Two-sided market: a progress report. The Rand Journal of Economics, 3(35), 645-667.

Savall, H., \& Zardet, V. (2004). Recherche en sciences de gestion: Approche qualimétrique - Observer l'objet complexe. Paris: Economica.

Schumpeter, J. A. (1939). Business cycles: a theoretical, historical, and statistical analysis of the capitalist process. New York: McGraw-Hill.

Stake, R. (1995). The art of case study research. Thousand Oaks: Sage. 
Sternitzke, C. (2010). Knowledge sources, patent protection, and commercialization of pharmaceutical innovations. Research Policy, 39, 810 821.

Teece, D. J. (1986). Profiting from technological innovation: implications for integration, collaboration, licensing and public policy. Research Policy, 15, 285-305.

Teece, D. J. (2007). Explicating dynamic capabilities: the nature and microfoundations of (sustainable) enterprise performance. Strategic Management Journal, 28(13), 1319-1350.

Teece, D. J. (2010). Business models, business strategy, and innovation. Long Range Planning, 43, 172-194.

Teece, D. J., Pisane, G., \& Shuen, A. (1997). Dynamic capabilities and strategic management. Strategic Management Journal, 18(7), 509 533. AQ8

Verona, G., \& Ravasi, D. (2003). Unbundling dynamic capabilities: an exploratory study of continuous product innovation. Industrial and Corporate Change, 12(3), 577-606.

Wang, C. L., \& Ahmed, P. K. (2007). Dynamic capabilities: a review and research agenda. International Journal of Management Reviews, 9(1), 31-51.

Yin, R. (1989). Case study research: design and methods (Rev.ed.). Newbury Park: Sage Publishing.

Zahra, S. A., \& George, G. (2002). Absorptive capacity: a review, reconceptualization, and extension. Academy of Management Review, 27(2), 185-203.

${ }^{1}$ CHEMIN: Chemins de l'Histoire E-guidés par Mobiles Intégrants le NFC

${ }^{2}$ MBDS: mobiquité, base de données et intégration de systèmes

${ }^{3}$ An API is an application programming interface, which is a plug-in that enables applications to exchange data.

${ }^{4}$ Transports Public Genevois is an iPhone application developed by GFI for Geneva public transportation that provides bus timetables and traffic information in real time.

5 Our own translation.

${ }^{6}$ Reich et al. (2014, p. 597) for example, investigating project management in IT demonstrated 
that the process consisting in aligning knowledge within project teams had a larger impact on project value than the production of knowledge.

7 Our translation. 